Revista Brasileira de Agricultura Irrigada v.11, nº.8, p. 2098 - 2110, 2017

ISSN 1982-7679 (On-line)

Fortaleza, CE, INOVAGRI - http://www.inovagri.org.br

DOI: $10.7127 /$ rbai.v11n800685

Protocolo 685.17 - 25/05/2017 Aprovado em 21/09/2017

\title{
CRESCIMENTO DO GIRASSOL COM ÁGUAS DE DIFERENTES SALINIDADES, FONTES E DOSES DE NITROGÊNIO
}

\author{
Reginaldo Gomes Nobre ${ }^{1}$, Geovani Soares de Lima ${ }^{2}$, Hans Raj Gheyi ${ }^{3}$, Erbia Bressia \\ Gonçalves Araújo ${ }^{4}$, Lauriane Almeida dos Anjos Soares ${ }^{5}$, Welington Bezerra de Sousa ${ }^{6}$
}

\begin{abstract}
RESUMO
Objetivou-se com este trabalho, avaliar o crescimento do girassol cv. Embrapa 122/V -2000 irrigadas com água de distintos níveis salinos e sob diferentes fontes e doses de "N", em experimento conduzido em lisímetros, sob condições de ambiente protegido do Centro de Ciências e Tecnologia Agroalimentar da Universidade Federal de Campina Grande (CCTA/UFCG). Foi utilizado um delineamento em blocos casualizados com o esquema fatorial $(2 \times 3 \times 4)$, com três repetições, testando-se dois níveis de condutividade elétrica da água - $\mathrm{CEa}\left(\mathrm{CEa}_{1}-0,3 \mathrm{e} \mathrm{CEa}_{2}-3,0 \mathrm{dS} \mathrm{m} \mathrm{m}^{-1}\right)$, três fontes de $\mathrm{N}$ (ureia, sulfato de amônio e nitrato de cálcio) e quatro doses de nitrogênio $\left(\mathrm{N}_{1}-40, \mathrm{~N}_{2}-80, \mathrm{~N}_{3}-120\right.$ e $\left.\mathrm{N}_{4}-160 \mathrm{mg} \mathrm{kg}^{-1}\right)$. Constatou-se que a irrigação com água salina afetou o crescimento das plantas de girassol, provocando reduções no número de folhas, na altura das plantas, na massa foliar (fresca e seca), na área foliar e na razão de área foliar; o fornecimento de nitrogênio promoveu aumento na massa fresca e seca de folhas e área foliar e as fontes de n, ureia e o nitrato de cálcio contribuíram para o incremento no número de folhas aos 25 das e altura das plantas aos 25, 35 e 70 das; a interação entre os fatores estudados não influenciou nenhuma das variáveis estudadas.
\end{abstract}

Palavras-chave: Helianthus annuus L, adubação, estresse salino.

\section{GROWTH OF SUNFLOWER WITH WATERS OF DIFFERENT SALINITIES, SOURCES AND DOSES OF NITROGEN}

\footnotetext{
${ }^{1}$ Doutor em Engenharia Agrícola, Professor Adjunto, Universidade Federal de Campina Grande - CCTA/UFCG, Pombal, PB, Brasil. E-mail: rgomesnobre@yahoo.com.br

${ }^{2}$ Pós-Doutorando em Engenharia Agrícola, PNPD/CAPES, Universidade Federal de Campina GrandeCTRN/UFCG, Campina Grande, PB, Brasil. E-mail: geovanisoareslima@gmail.com.

${ }^{3}$ Professor Visitante Sênior Nacional/CAPES, Universidade Federal do Recôncavo da Bahia, Cruz das Almas, BA, Brasil. E-mail: hans@pq.cnpq.br.

${ }^{4}$ Mestre em Horticultura Tropical, Universidade Federal de Campina Grande - CCTA/UFCG, Pombal, PB, Brasil. E-mail: erbiabressiaaga@gmail.com.

${ }^{5}$ Pós-Doutoranda em Engenharia Agrícola, PDJ/CNPq Universidade Federal de Campina Grande-CTRN/UFCG, Campina Grande, PB, Brasil. E-mail: laurispo.agronomia@gmail.com

${ }^{6}$ Mestre em Sistemas Agroindustriais, Universidade Federal de Campina Grande, CCTA/UFCG, Pombal, PB, Brasil. E-mail: welingtonbezerra@yahoo.com.br.
} 


\begin{abstract}
The objective of this study was to evaluate the growth of sunflower cv. Embrapa 122 / V 2000 irrigated with water of different saline levels and under different sources and doses of "N", in an experiment conducted in lysimeters under protected environment conditions of the Center of Sciences and Technology Agrifood of the Federal University of Campina Grande (CCTA / UFCG). A randomized block design with a factorial scheme $(2 \times 3 \times 4)$, with three replicates, was used to test two levels of water electrical conductivity - $\mathrm{CEa}\left(\mathrm{CEa}_{1}-0,3\right.$ and $\mathrm{CEa}_{2}-3,0 \mathrm{dS} \mathrm{m}^{-1}$ ), three $\mathrm{N}$ sources (urea, ammonium sulfate and calcium nitrate) and four nitrogen doses $\left(\mathrm{N}_{1}-40, \mathrm{~N}_{2}-80, \mathrm{~N}_{3}-120\right.$ and $\left.\mathrm{N}_{4}-160 \mathrm{mg} \mathrm{kg}^{-1}\right)$. It was verified that irrigation with saline water affected the growth of sunflower plants, causing reductions in the number of leaves, plant height, leaf mass (fresh and dry), leaf area and leaf area ratio; nitrogen supply promoted an increase in fresh and dry mass of leaves and leaf area and $n$, urea and calcium nitrate sources contributed to the increase in the number of leaves at 25 das and plant height at 25,35 and 70 das; the interaction between the factors studied did not influence any of the studied variables.
\end{abstract}

Key words: Helianthus annuus L, fertilization, salt stress.

\section{INTRODUÇÃO}

A exploração dos recursos hídricos de boa qualidade tem-se intensificado em todo o mundo, principalmente devido à necessidade de expansão das áreas agrícolas, provocada pelo crescimento populacional mundial, e à consequente necessidade do uso de águas, consideradas de qualidade inferior (AYERS e WESTCOT, 1999), em especial nas regiões áridas e semiáridas, onde as precipitações são escassas e apresenta uma distribuição irregular. No Nordeste brasileiro, a maior parte das águas utilizadas na irrigação contêm teores relativamente elevados de sais, sendo frequentemente encontrados valores $\mathrm{da}$ condutividade elétrica da ordem de 0,2 a 5,0 dS $\mathrm{m}^{-1}$ (AUDRY e SUASSUNA, 1995).

$\mathrm{O}$ expressivo aumento demográfico criou a necessidade de se aumentar a produção mundial de alimentos, aliado ao acelerado desenvolvimento industrial, fez aumentar a demanda de água. Visando contribuir para mitigar a escassez de recursos hídricos na região nordeste do Brasil, vários estudos têm mostrado a possibilidade de utilização de águas salinas na agricultura (SILVA et al., 2009; NOBRE et al., 2010; OLIVEIRA et al., 2010; SANTOS JUNIOR et al., 2011; GUEDES FILHO et al., 2013). Contudo, o uso de águas com altas concentrações de sais podem provocar efeitos tóxicos, causando distúrbios funcionais e danos no metabolismo das plantas (SILVA et al., 2009).

Outro fator importante no manejo de culturas é a nutrição mineral e entre os principais elementos essenciais para as plantas destaca-se o nitrogênio (MILLER e CRAMER, 2004), devido às suas funções no metabolismo das plantas e ao fato de integrar muitas biomoléculas, tais como proteínas, ácidos nucleicos e aminoácidos (MCALLISTER et al., 2012). Por outro lado, a fertilização nitrogenada não só promove crescimento das plantas, como também pode atenuar o efeito da salinidade sobre estas. Este efeito ocorre porque nessas condições há maior acumulação de compostos orgânicos contendo nitrogênio (prolina, aminoácidos livres e glicina betaína) (MUNNS e TESTER, 2008). O nitrogênio tem como principal fonte o íon nitrato $\left(\mathrm{NO}_{3}{ }^{-}\right)$, mais abundante do que o íon amônio $\left(\mathrm{NH}_{4}{ }^{+}\right) \mathrm{em}$ torno das raízes (MILLER et al., 2007). Del Amor et al. (2000) referem que este nutriente pode atenuar o efeito do estresse salino sobre as culturas em virtude de competição na absorção radicular entre os íons nitrato e cloreto, pelo que um aumento na concentração de nitrato na zona radicular pode inibir uma maior absorção de cloreto pela planta.

Há que se considerar também, que grande parte das fontes de nitrogênio disponíveis no 
mercado são sais, susceptíveis de aumentar a condutividade elétrica do solo (SANGOI et al., 2009). Sendo assim, principalmente quando o uso de água salina é inevitável, na escolha dos adubos nitrogenados deve dar-se especial atenção ao índice de salinidade dos mesmos. Entretanto, pesquisas têm demonstrado que a acumulação desse nutriente na planta eleva a sua capacidade de ajustamento osmótico em condições de salinidade (SILVA et al., 2008).

O girassol é uma oleaginosa pertencente à família Asteraceaee que vem despertando atenção especial em todo o mundo, pois além da produção de aquênios, está sendo largamente cultivada visando o fornecimento de matéria-prima para a indústria alimentar e com potencial capaz de fomentar o programa Biodiesel no Brasil (SANTOS JÚNIOR et al., 2011).

Nestas condições, com o presente trabalho, pretendeu-se avaliar o crescimento do girassol cv. Embrapa 122/V-2000 irrigadas com água de distintos níveis salinos e sob diferentes fontes e doses de nitrogênio.

\section{MATERIAL E MÉTODOS}

O ensaio decorreu em lisímetros de drenagem instalados em ambiente protegido sob condições de campo no Centro de Ciências e Tecnologia Agroalimentar (CCTA) da Universidade Federal de Campina Grande (UFCG) localizado no município de Pombal, $\mathrm{PB}$, situado a $6^{\circ} 48^{\prime} 16^{\prime \prime} \mathrm{S}, 37^{\circ} 49^{\prime} 15^{\prime \prime} \mathrm{W}$ e altitude média de $144 \mathrm{~m}$.

Adotou-se um delineamento experimental em blocos inteiramente casualizados, utilizando um esquema fatorial $2 \times 3 \times 4$, com três repetições, cujos tratamentos consistiram no uso de dois níveis de condutividade elétrica da água de irrigação- $\mathrm{CEa}\left(\mathrm{CEa}_{1}-0,3\right.$ e $\mathrm{CEa}_{2}-3,0$ $\mathrm{dS} \mathrm{m}^{-1}$ ), três fontes de nitrogênio (ureia, sulfato de amónio e nitrato de cálcio) e de quatro doses de adubação nitrogenada $\left(\mathrm{N}_{1^{-}} 40\right.$, $\mathrm{N}_{2}-80, \mathrm{~N}_{3}-120$ e $\mathrm{N}_{4}-160 \mathrm{mg} \mathrm{kg}^{-1}$ ), sendo os valores fixados com base em ensaios realizados anteriormente (NOBRE et al., 2010; GUEDES FILHO et al., 2013).

O nível de salinidade da água mais baixo $\left(0,3 \mathrm{dS} \mathrm{m}^{-1}\right)$ correponde à salinidade da água do sistema de abastecimento local. A água com CEa de 3,0 dS m${ }^{-1}$ foi preparada mediante adição à água do sistema de abastecimento local de cloreto de sódio, cuja quantidade foi determinada, conforme Rhoades et al. (2000), pela equação Q $\left(\mathrm{mg} \mathrm{L}^{-1}\right)=\mathrm{CEa} \times 640$, onde

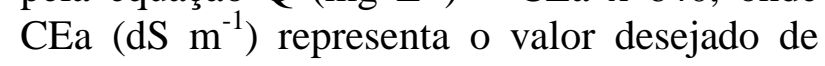
salinidade da água. Estudou-se o efeito da CEa de 3,0 dS m$~^{-1}$ por este valor corresponder a um nível de salinidade frequentemente encontrado nas águas da região semiárida nordestina.

Utilizou-se a cultivar de girassol Embrapa 122/V-2000 já que, segundo EMBRAPA (2006), este material genético se destaca pela precocidade, produtividade, qualidade e teor de óleo nas sipselas. As sementes foram cedidas pela Embrapa Algodão.

Utilizaram-se vasos adaptados como lisímetros de drenagem de $18 \mathrm{~L}$ de capacidade, preenchidos com $0,5 \mathrm{~kg}$ de brita e $1 \mathrm{~kg}$ de cascalho (os quais cobriam a base do lisímetro) e $13 \mathrm{~kg}$ de material de solo (Neossolo Regolítico Eutrófico típico de textura francoarenosa) não salino e não sódico, devidamente destorroado e proveniente do município de Pombal, Paraíba, Brasil, cujas características físico-químicas (Tabela 1) foram determinadas no Laboratório de Solos e Nutrição de Plantas do CCTA/UFCG, segundo metodologia proposta por Claessen (1997).

Tabela 1. Características físicas e químicas do solo utilizado no ensaio

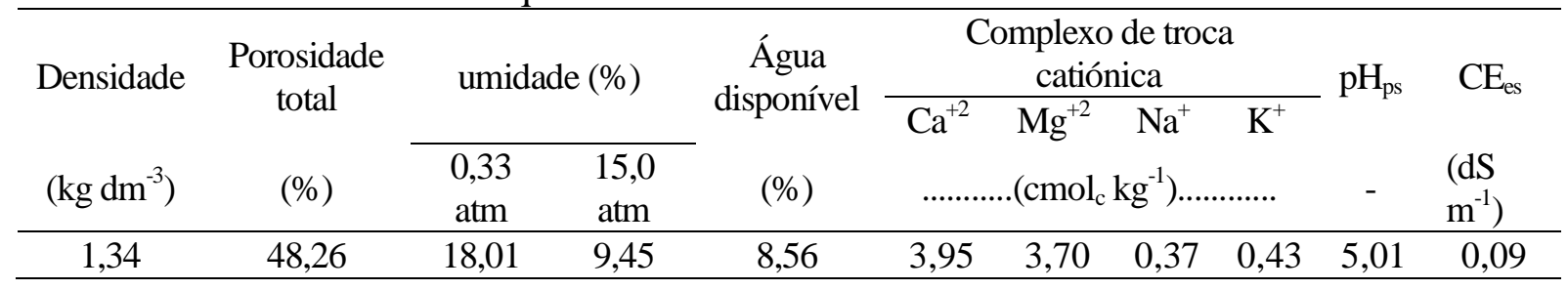


Nota: $\mathrm{Ca}^{2+}$ e $\mathrm{Mg}^{2+}$ extraídos com $\mathrm{KCl} 1 \mathrm{~mol} \mathrm{~L}^{-1}$ a pH 7,0; $\mathrm{Na}^{+}$e $\mathrm{K}^{+}$extraídos utilizando $\mathrm{NH}_{4} \mathrm{OAc} 1 \mathrm{~mol} \mathrm{~L}^{-1}$ apH 7,0; $\mathrm{pH}_{\mathrm{ps}}-\mathrm{pH}$ da pasta de saturação; $\mathrm{CE}_{\mathrm{es}}$ - condutividade elétrica do extrato de saturação

Para completar o volume do lisímetro, colocaram-se $4 \mathrm{~kg}$ do material de solo misturado com $3 \%$ (peso total do material do solo - $17 \mathrm{~kg})$ de esterco bovino curtido $(6,3 \mathrm{~g}$ de $\mathrm{N} \mathrm{kg}^{-1}, 1,28 \mathrm{~g}$ de $\mathrm{P} \mathrm{kg}^{-1}$ e $0,53 \mathrm{~g} \mathrm{de} \mathrm{K} \mathrm{kg}^{-1}$ ). Os vasos, dispostos em fileiras duplas espaçadas de $0,9 \mathrm{~m}$, com $0,6 \mathrm{~m}$ entre fileiras simples e $0,2 \mathrm{~m}$ entre vasos dentro da fileira, possuíam furos na base para permitir o acompanhamento do volume drenado e a estimativa do consumo de água pela cultura. $\mathrm{O}$ material de solo após ser acondicionado nos vasos foi colocado à capacidade de campo usando a água correspondendo ao tratamento em questão.

A adubação nitrogenada foi fracionada em 4 aplicações, sendo $1 / 4$ do nitrogênio aplicado em fundação e os restantes 3/4 divididos por 3 aplicações feitas, via fertirrigação, aos 15, 30 e 45 dias após a semeadura (DAS). Para o nível $\mathrm{N}_{1}(40 \mathrm{mg}$ de N) aplicou-se por vaso $0,27 \mathrm{~g}$ de ureia, $0,57 \mathrm{~g}$ sulfato de amónio e 1,03 g nitrato de cálcio. A adubação potássica e fosfatada foi realizada de acordo com a análise química do solo e seguindo as necessidades nutritivas da cultura (150 e $300 \mathrm{mg} \mathrm{kg}^{-1}$, respectivamente). Visando obter um equilíbrio nutricional entre as distintas fontes de nutrientes foi utilizado sulfato de potássio $\left(\mathrm{K}_{2} \mathrm{SO}_{4}\right)$ nos tratamentos contendo ureia e nitrato de cálcio, e cloreto de potássio $(\mathrm{KCl})$ nos tratamentos que incluiam sulfato de amónio, sendo estes sais aplicados em cova, a $5 \mathrm{~cm}$ de profundidade e $10 \mathrm{~cm} \mathrm{de}$ distância do colo da planta.

A semeadura foi realizada no dia 23 de maio de 2012, com 7 sementes por vaso, colocadas a $2 \mathrm{~cm}$ de profundidade $\mathrm{e}$ distribuídas de forma a ficarem equidistantes. A emergência das plântulas teve inicio no $3^{\circ}$ DAS e continuou até o $13^{\circ}$ DAS. Aos 15 DAS realizou-se o primeiro desbaste, deixando-se apenas três plantas por vaso as de maior vigor e aos 25 e 35 DAS realizaram-se novos desbastes tendo-se eliminado uma planta por vaso.

Após a semeadura, irrigou-se diariamente, aplicando-se, em cada vaso, água com a salinidade correspondente ao respectivo tratamento, tomando como base o resultado do balanço hídrico, efetuado, acrescido de aproximadamente de $10 \%$ como a fração de lixiviação.

Para avaliação do efeito dos tratamentos sobre o crescimento do girassol determinou-se o número de folhas (NF) aos 25, 35 e 89 DAS, a altura de planta (AP) aos 25, 35 e 70 DAS, e a massa foliar fresca e seca (MFF e MFS) aos 25, 35 e 89 DAS, e aos 35 DAS determinou-se a área foliar (AF) e a razão da área foliar (RAF). Na contagem do número de folhas consideraram-se as que estavam totalmente expandidas, com comprimento mínimo de $2 \mathrm{~cm}$ e que apresentavam no mínimo $50 \%$ da sua área fotossinteticamente ativa. A altura da planta foi medida, mensurando-se a distância entre o colo da planta e ápice caulinar, utilizando fita métrica graduada em milímetros.

A massa das folhas foi determinada cortando a haste de cada planta rente ao solo, separando-se as folhas; após acondicionamento em sacos de papel devidamente identificados, as folhas foram postas a secar em estufa de circulação de ar forçado, a $60^{\circ} \mathrm{C}$, até obtenção de massa constante para determinação da MFS. $\mathrm{Na}$ determinação da área foliar, mediu-se o comprimento e largura de todas as folhas que tinham largura mínima de $2 \mathrm{~cm}$ e, em seguida, multiplicaram-se os valores obtidos pelo fator de ajustamento $(\mathrm{K}=0,7)$ estimado pela equação sugerida por Fagundes et al. (2007). A RAF foi obtida de acordo com a metodologia de Ferri et al. (1985), conforme Eq 1:

$$
\mathrm{RAF}=\frac{\mathrm{AF}}{\mathrm{FSPA}}\left(\mathrm{cm}^{2} \mathrm{~g}^{-1}\right)
$$

em que:

RAF - Razão da área foliar $\left(\mathrm{cm}^{2} \cdot \mathrm{g}^{-1}\right)$,

$\mathrm{AF}$ - Área foliar $\left(\mathrm{cm}^{2}\right)$,

FSPA - Fitomassa seca da parte aérea (g).

Os dados obtidos foram avaliados mediante análise de variância pelo teste ' $\mathrm{F}$ ' aos níveis de 0,05 e 0,01 de probabilidade e nos casos de significância, realizou-se análise de regressão polinomial para o fator doses de $\mathrm{N}$; os fatores salinidade da água de irrigação e 
fonte de $\mathrm{N}$ foram avaliados conforme o teste de Tukey a 0,05 da probabilidade, utilizando-se em todas as análises o software estatístico SISVAR-ESAL.

\section{RESULTADOS E DISCUSSÃO}

Com base nos resultados do teste $\mathrm{F}$ (Tabela 2), constata-se haver um efeito significativo $(\mathrm{p}<0,01)$ dos níveis de salinidade da água de irrigação sobre as variáveis número de folhas (aos 25, 35 e 89 DAS) e a altura da planta (aos 25, 35 e 70 DAS). Em relação ao fator fonte de $\mathrm{N}$ observou-se efeito significativo sobre o NF aos 35 DAS $(\mathrm{p}<0,05)$ e para a AP nas três datas objeto de estudo $(p<0,01)$. As doses de $\mathrm{N}$ não provocaram qualquer efeito significativo sobre NF e AP. As diferentes combinações de interação entre os fatores de variação (nível salino, fontes e doses de $\mathrm{N}$ ) também não afetaram significativamente $(\mathrm{p}>$ $0,05)$ as duas variáveis em análise (NF e AP), evidenciando que as diferentes fontes e doses de $\mathrm{N}$ se comportaram de maneira semelhante em diferentes níveis de salinidade da água utilizada. Nobre et al. (2010), analisando os efeitos da irrigação com água com diferentes salinidade e teor de nitrogênio no crescimento e floração do girassol também verificaram não haver interação entre os fatores referidos.

Tabela 2. Resumo do teste F para número de folhas (NF) aos 25, 35 e 89 DAS, e altura das plantas (AP) aos 25, 35 e 70 DAS do girassol cv. Embrapa 122/V-2000 aos 50 e 70 DAS cultivado sob salinidade da água de irrigação, fontes e doses de nitrogênio

\begin{tabular}{lcccccc}
\hline & \multicolumn{6}{c}{ Teste F } \\
\cline { 2 - 7 } Origem da variação & \multicolumn{7}{c}{ NF } & \multicolumn{5}{c}{ AP } \\
\cline { 2 - 7 } & 25 & 35 & 89 & 25 & 35 & 70 \\
\hline Salinidade (S) & $* *$ & $* *$ & $* *$ & $* *$ & $* *$ & $* *$ \\
Fontes de N (FN) & $\mathrm{ns}$ & $*$ & $\mathrm{~ns}$ & $* *$ & $* *$ & $* *$ \\
Doses de N (DN) & $\mathrm{ns}$ & $\mathrm{ns}$ & $\mathrm{ns}$ & $\mathrm{ns}$ & $\mathrm{ns}$ & $\mathrm{ns}$ \\
Reg. linear & - & - & - & - & - & - \\
Reg.quadrática & - & - & - & - & - & - \\
Interação S x FN & $\mathrm{ns}$ & $\mathrm{ns}$ & $\mathrm{ns}$ & $\mathrm{ns}$ & $\mathrm{ns}$ & $\mathrm{ns}$ \\
Interação S x DN & $\mathrm{ns}$ & $\mathrm{ns}$ & $\mathrm{ns}$ & $\mathrm{ns}$ & $\mathrm{ns}$ & $\mathrm{ns}$ \\
Interação FN x DN & $\mathrm{ns}$ & $\mathrm{ns}$ & $\mathrm{ns}$ & $\mathrm{ns}$ & $\mathrm{ns}$ & $\mathrm{ns}$ \\
Interação (SxFNxDN) & $\mathrm{ns}$ & $\mathrm{ns}$ & $\mathrm{ns}$ & $\mathrm{ns}$ & $\mathrm{ns}$ & $\mathrm{ns}$ \\
Bloco & $\mathrm{ns}$ & $\mathrm{ns}$ & $\mathrm{ns}$ & $\mathrm{ns}$ & $\mathrm{ns}$ & $\mathrm{ns}$ \\
CV (\%) & 11,96 & 12,35 & 20,36 & 11,37 & 12,34 & 11,22 \\
\hline
\end{tabular}

Nota: $\mathrm{ns}, * *, *$ respectivamente não significativo e significativo a $\mathrm{p}<0,01$ e a $\mathrm{p}<0,05$

$\mathrm{O}$ efeito da salinidade da água de irrigação sobre o NF do girassol observado nas 3 determinações efetuadas é explicitado na Figura 1A, onde se pode observar que as plantas irrigadas com água mais salina (CEa 3,0 dS m${ }^{-1}$ ) quando comparadas com as plantas sujeitas a irrigação com água de CEa $0,3 \mathrm{dS} \mathrm{m}^{-}$ , sofreram reduções do NF aos 25,35 e 89 DAS respectivamente de 15,38, 10,67 e $33,86 \%$. Segundo Tester e Davenport (2003), o aumento da concentração salina na solução do solo reduz o potencial osmótico desta, dificultando a absorção de água pelas plantas, provocando efeitos negativos de ordem nutricional, toxicidade e/ou interferindo na disponibilidade dos íons $\mathrm{Cl}^{-}$e $\mathrm{Na}^{+}$e desta forma afeta o crescimento das plantas. Travasssos et al. (2012), estudando o crescimento e desenvolvimento de variedades de girassóis cultivadas em ambiente protegido e regadas com água com $\mathrm{CEa}$ entre 0,6 e $5,4 \mathrm{dS} \mathrm{m}^{1}$, verificaram, aos $50 \mathrm{DAS}$, que o aumento unitário da CEa levou a reduções do $\mathrm{NF}$ de 7,1 e 7,9\%, respectivamente para as 


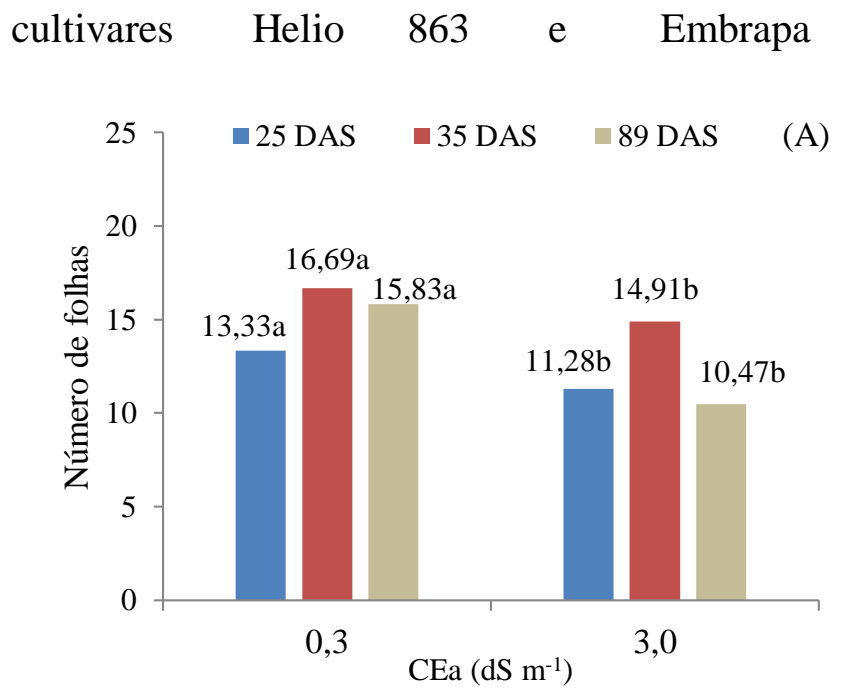

122/V2000.

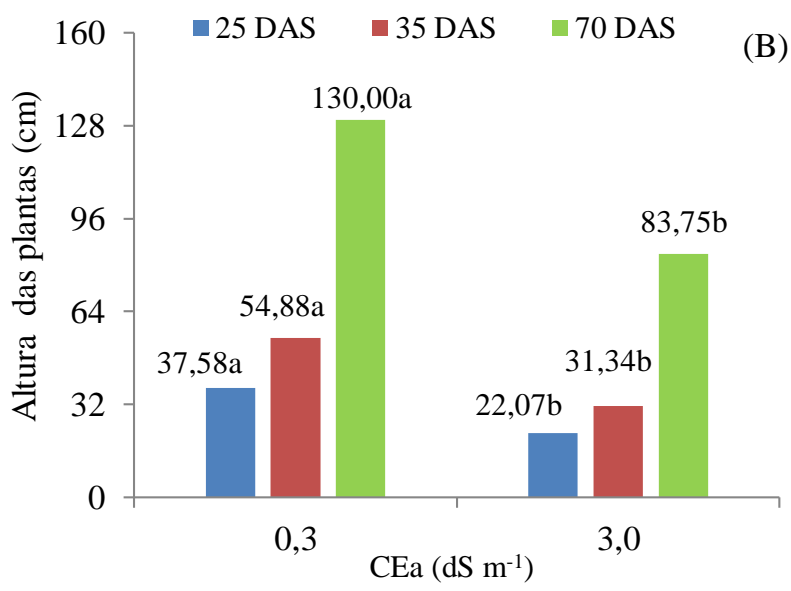

Médias seguidas pela mesma letra nas colunas, não diferem entre si a nível de 0,05 de probabilidade pelo teste de Tukey.

Figura 1. Número de folhas aos 25, 35 e 89 DAS (A) e altura das plantas do girassol cv. Embrapa 122/V- 2000 aos 25, 35 e 70 DAS (B) em função da salinidade da água de irrigação - (CEa).

O incremento da salinidade, como já referido, afetou também a altura das plantas do girassol tendo-se observado (Figura 1B) que, em comparação com as plantas irrigadas com água com CEa $0,3 \mathrm{dS} \mathrm{m}^{-1}$, os valores de AP das plantas sujeitas à irrigação com água de CEa $3,0 \mathrm{dS} \mathrm{m}^{-1}$ são inferiores em 41,27\% $(15,5 \mathrm{~cm})$, $42,89 \%(23,5 \mathrm{~cm})$ e $35,57 \%(46,2 \mathrm{~cm})$, respectivamente aos 25, 3570 DAS. Segundo Oliveira et al. (2011), as plantas sob estresse salino sofrem alterações morfológicas e anatômicas, e consequentemente, redução do efeito da transpiração como mecanismo para manter a sua turgescência foliar. Travassos et al. (2011), analisando o crescimento inicial do girassol cv. Embrapa 122-V2000 sob diferentes CEa $\left(0,5\right.$ a $\left.5,0 \mathrm{dS} \mathrm{m}^{-1}\right)$ aos $40 \mathrm{DAS}$, também notaram que o incremento salino contribui significativamente para a redução da AP.

$O$ fato da adubação nitrogenada não ter tido efeito significativo $(p>0,05)$ sobre o NF e a AP de girassol nas distintas datas de avaliação (Tabela 2) dever-se-á ao uso no ensaio de esterco bovino contendo $\mathrm{N}$ e outros nutrientes. Por razões semelhantes, Bruginski e Pissaia (2002), estudando os efeitos da aplicação de doses de nitrogênio variando entre 0 e $125 \mathrm{~kg}$ ha $^{-1}$ sobre a cultura do girassol, não constataram efeitos significativos sobre a produção de massa seca de caule, pecíolo, folhas e capítulo, tendo considerado a presença de matéria orgânica existente no solo como um dos fatores que contribuíram para este resultado.

Contrariamente observou-se efeito significativo $(\mathrm{p}<0,05)$ do fator fonte de $\mathrm{N}$ sobre o número de folhas aos 35 DAS (Figura 2A), e sobre a altura da planta aos 25 e 35 DAS (Figura 2B). Nas Figura 2A e 2B observa-se ainda que os maiores valores de NF aos 25 DAS e os valores de AP registrados em todas as datas foram obtidos nos tratamentos em que as plantas receberam ureia $(\mathrm{U})$ e nitrato de cálcio (NC) como fonte de $\mathrm{N}$, mas esses valores não diferem significativamente entre si. No caso do número de folhas e da altura da planta os valores obtidos com a aplicaçao de sulfato de amónio (SA) são inferiores aos obtidos com ureia e nitrato de cálcio. Oliveira et al. (2010), em ensaio testando o efeito da CEa e de distintas fontes de N (ureia, nitrato de cálcio e sulfato de amónio) sobre o crescimento inicial do girassol também constataram, aos 40 DAS, que as plantas sujeitas a adubação com ureia e nitrato de cálcio não diferiram estatisticamente entre si em termos de NF e AP. No entanto, as que foram adubadas com sulfato de amónio apresentaram valores de NF e AP mais elevados, resultado que contraria os observados no presente estudo. 

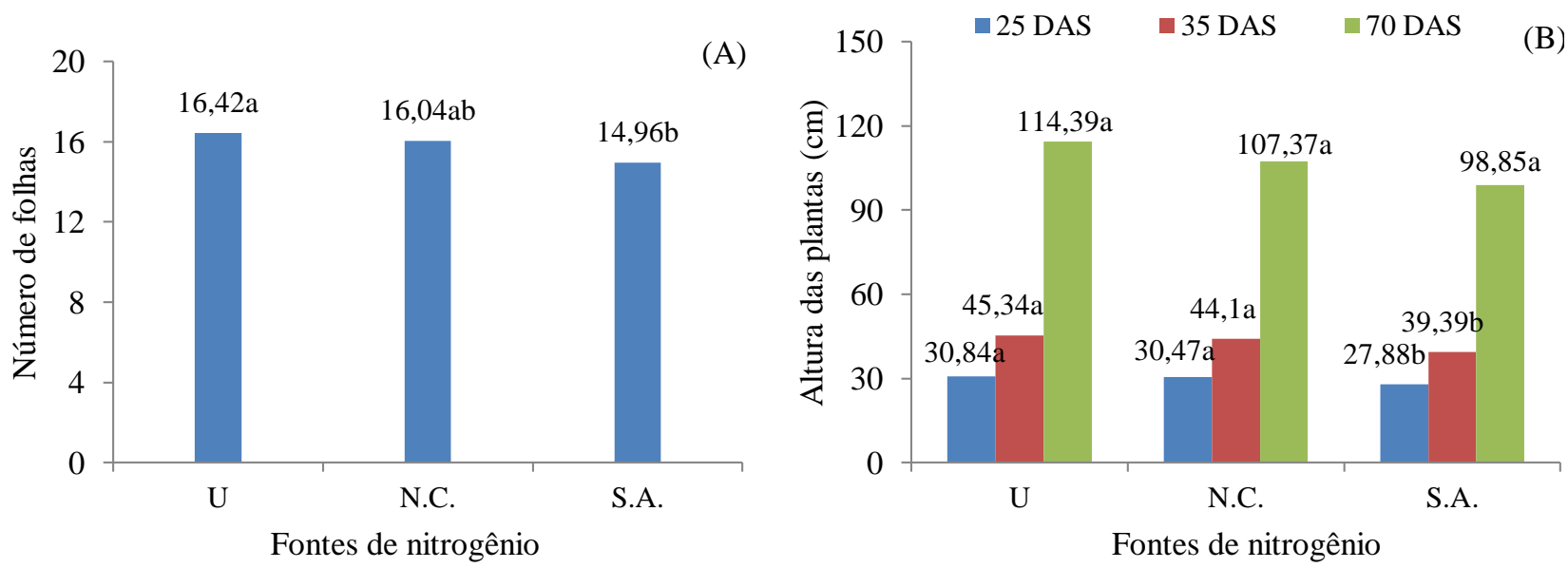

(U= ureia; $\mathrm{NC}=$ nitrato de cálcio; $\mathrm{AS}=$ sulfato de amónio). Médias seguidas pela mesma letra nas colunas, não diferem entre si a nível de 0,05 de probabilidade pelo teste de Tukey.

Figura 2. Número de folhas aos 25 DAS (A) e altura de planta cv. Embrapa 122/V- 2000 aos 25, 35 e 70 DAS (B) em função de fontes de nitrogênio.

Relativamente à massa foliar, observa-se na Tabela 3, que houve efeito significativo dos níveis de salinidade da água de irrigação $(\mathrm{p}<$ $0,01)$, e do fator doses de nitrogênio $(\mathrm{p}<0,05)$ sobre a massa foliar fresca (MFF) e seca (MFS) aos 25, 35 e 89 DAS, e sobre a área foliar (AF) aos 35 DAS. Observa-se igualmente efeito dos dois fatores referidos sobre a razão de área foliar (RAF) $(\mathrm{p}<0,05)$. Aos 35 DAS as fontes de $\mathrm{N}$ e a combinação de fatores não tiveram efeito significativo sobre nenhuma das variáveis referidas na Tabela 3 (MFF, MFS, AF e RAF). Oliveira et al. (2010), avaliando o efeito da salinidade e das fontes de $\mathrm{N}$, aos 40 DAS, sobre a altura, número de folhas, área foliar e matéria seca total do girassol, encontraram efeito significativo apenas para AP.

Tabela 3 - Resumo do teste F para a massa foliar fresca (MFF) e seca (MFS) aos 25, 35 e 89 DAS; área foliar (AF) (aos 35 DAS) e razão de área foliar (RAF) (aos 35 DAS) do girassol cv. Embrapa 122/V-2000 cultivado sob salinidade da água de irrigação, fontes e doses de nitrogênio

\begin{tabular}{|c|c|c|c|c|c|c|c|c|}
\hline \multirow{4}{*}{ Origem da Variação } & \multicolumn{8}{|c|}{ Teste F } \\
\hline & \multirow{2}{*}{\multicolumn{2}{|c|}{ MFF }} & & & \multirow{3}{*}{$\begin{array}{r}\text { AF } \\
35 \\
\end{array}$} & \multirow{3}{*}{$\begin{array}{r}\text { RAF } \\
35 \\
\end{array}$} \\
\hline & & & Dias após a semeadura & & & & & \\
\hline & 25 & 35 & 89 & 25 & 35 & 89 & & \\
\hline Salinidade (S) & $* *$ & $* *$ & $* *$ & $* *$ & $* *$ & $* *$ & $* *$ & $*$ \\
\hline Fontes de $\mathrm{N}(\mathrm{FN})$ & ns & ns & ns & ns & ns & ns & ns & ns \\
\hline Doses de N (DN) & $*$ & $*$ & $*$ & $*$ & $*$ & $*$ & $*$ & $*$ \\
\hline Reg. linear & ns & ns & ns & ns & $* *$ & $* *$ & $*$ & $* *$ \\
\hline Reg.quadrática & $*$ & ns & ns & $*$ & ns & ns & $*$ & ns \\
\hline Interação S x FN & ns & ns & ns & ns & ns & ns & ns & ns \\
\hline Interação S x DN & ns & ns & ns & ns & ns & ns & ns & ns \\
\hline Interação FN x DN & ns & ns & $\mathrm{ns}$ & ns & ns & ns & ns & ns \\
\hline Interação (SxFNxDN) & ns & ns & ns & $\mathrm{ns}$ & ns & ns & ns & ns \\
\hline Bloco & ns & ns & ns & ns & $\mathrm{ns}$ & $\mathrm{ns}$ & ns & ns \\
\hline $\mathrm{CV}(\%)$ & 16,68 & 15,27 & 13,23 & 11,45 & 14,86 & 18,33 & 10,03 & 14,59 \\
\hline
\end{tabular}

Nota: ns, **, * respectivamente não significativo, e significativo a $\mathrm{p}<0,01$ e a $\mathrm{p}<0,05$ 
De acordo com o resumo do teste $\mathrm{F}$ apresentado na Tabela 3, a massa foliar fresca (MFF) foi influenciada significativamente pela salinidade da água e pela doses de nitrogênio aos 25,35 e 89 DAS. A Figura 3A mostra que as plantas, quando irrigadas com água de menor salinidade $\left(0,3 \mathrm{dS} \mathrm{m}^{-1}\right)$ produziram $52,89 \%$ mais MFF do que as sujeitas a irrigação com água com $\mathrm{CEa} 3,0 \mathrm{dS} \mathrm{m} \mathrm{m}^{-1}$. Segundo Yahya (1998) o efeito osmótico e a toxicidade provocada pela absorção excessiva

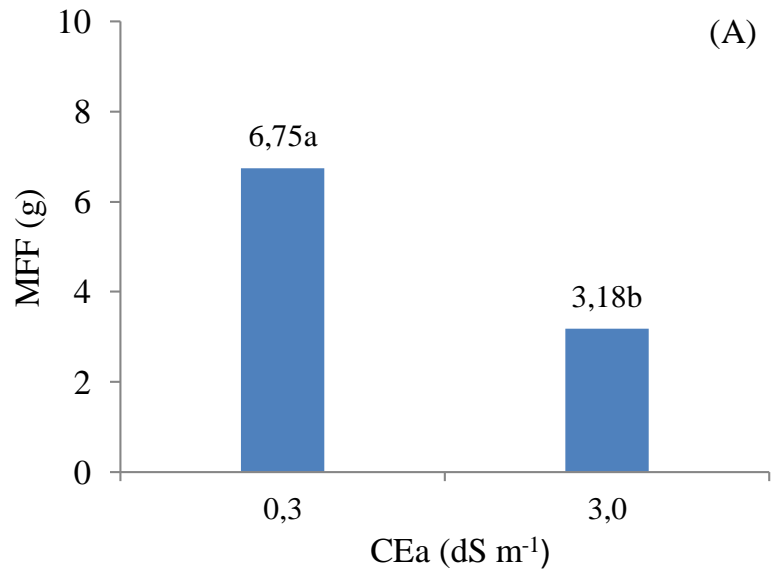

$\mathrm{Na}$ e $\mathrm{Cl}$ tem sido as principais causas da redução do crescimento e desenvolvimento das plantas. Santos Junior et al. (2011) em ensaio realizado com a cv.de girassol Embrapa 122/V2000 em hidroponia e utilizando água com diferentes salinidades, constataram uma redução da MFF de $43,45 \%$ entre as plantas produzidas com água com $\mathrm{CEa} 4,3 \mathrm{dS} \mathrm{m}^{-1} \mathrm{e}$ as produzidas com água com $\mathrm{CEa} 1,7 \mathrm{dS} \mathrm{m}^{-1}$, mostrando, assim, a sensibilidade da cultura à salinidade.

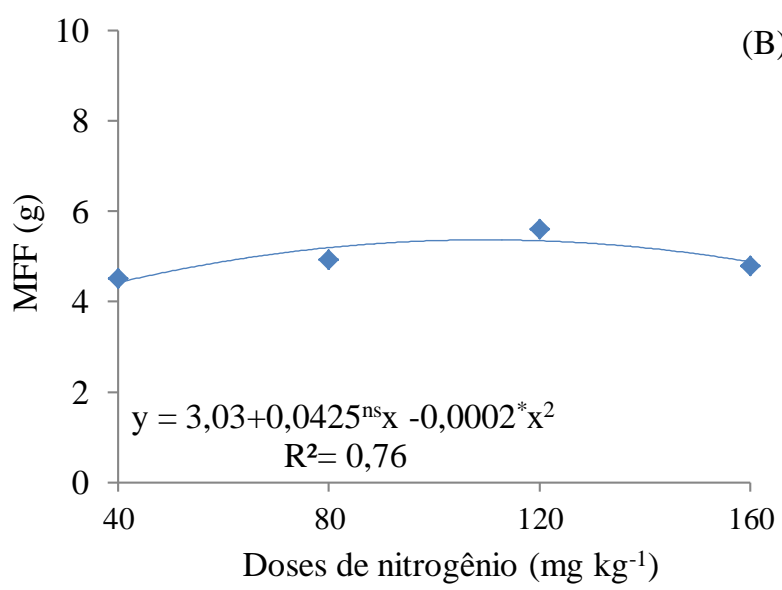

Médias seguidas pela mesma letra nas colunas, não diferem entre si a nível de 0,05 de probabilidade pelo teste de Tukey.

Figura 3. Massa foliar fresca (MFF) do girassol cv. Embrapa 122/V- 2000 aos 25 DAS em função da salinidade da água de irrigação-(CEa) (A) e das doses de nitrogênio (B).

Relativamente ao efeito do fator doses de N sobre a MFF (Figura 3B), e de acordo com a equação de regressão quadrática referida na figura 3B, é possível concluirque o maior valor de MFF $(5,29 \mathrm{~g})$ seria obtido com a dose de $105 \mathrm{mg}$ de $\mathrm{N}$. O conhecimento das doses de nitrogênio que ao longo do ensaio otimizam a produção de biomassa é importante, pois como referem Miller e Cramer (2004), o fornecimento de doses adequadas de nitrogênio durante todo o ciclo da cultura contribui parao crescimento e desenvolvimento das plantas. Santos et al. (2002) estudando o comportamento de cultivares de girassol em diferentes condições de umidade e adubação azotada, constataram que o efeito do nitrogênio sobre o rendimento ou acumulação de fitomassa depende da disponibilidade de água no solo, visto o principal mecanismo absorção desse nutriente é via fluxo em massa.

Como referido, e de acordo com o resumo da análise de variância constante do Tabela 3, houve efeito da conductividade eléctrica da água de de rega $(\mathrm{p}<0,01)$ sobre a massa seca das folhas do girassol nas três épocas de estudo. Analisando a Figura 4A observa-se que quando comparadas com as plantas irrigadas com água com $\mathrm{CEa}$ de $0,3 \mathrm{dS}$ $\mathrm{m}^{-1}$ as plantas sujeitas a rega com água com CEa 3,0 dS m${ }^{-1}$ tiveram decréscimos na MFS de $56,25,59,00$ e $52,15 \%$, respectivamente, aos 25, $35 \quad$ e $\quad 89 \quad$ DAS. 

DE NITROGÊNIO
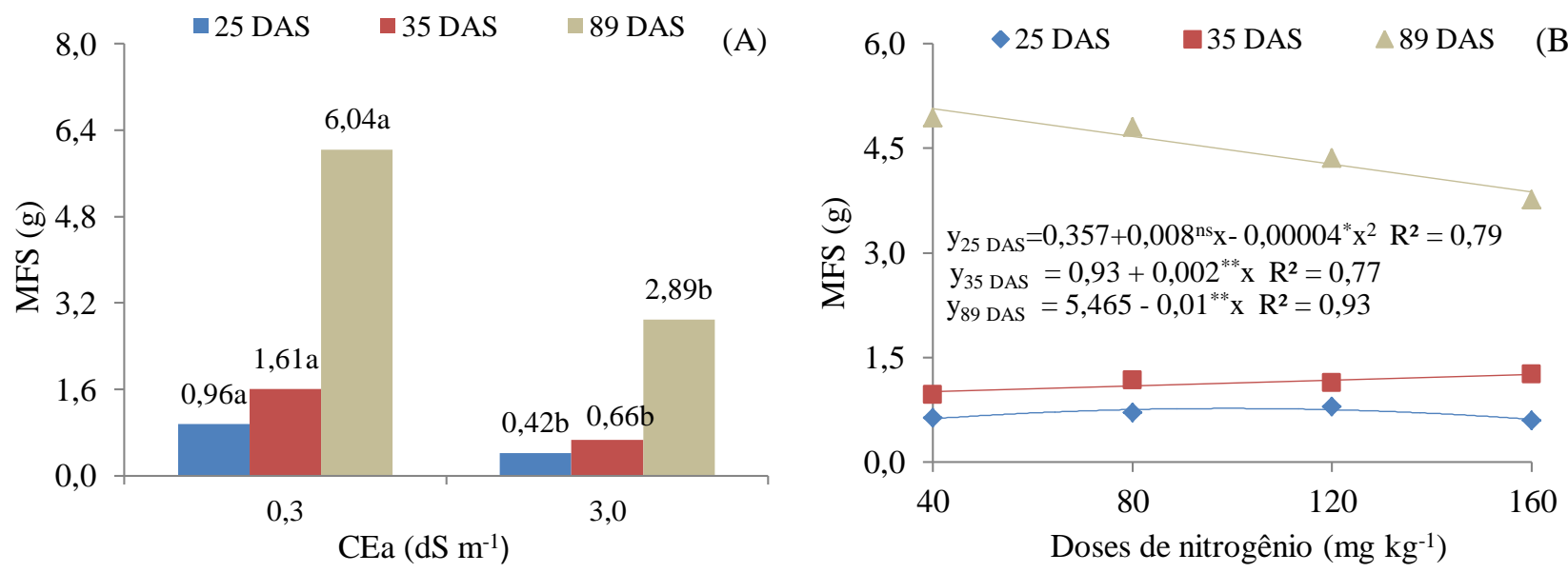

(B)

Médias seguidas pela mesma letra nas colunas, não diferem entre si a nível de 0,05 de probabilidade pelo teste de Tukey.

Figura 4. Massa foliar seca (MFS) do girassol cv. Embrapa 122/V- 2000aos 25, 35 e 89 DAS em função da salinidade da água de irrigação - (CEa) (A) e doses de nitrogênio (B).

Segundo Asch et al. (2000) a água de irrigação ou um solo com concentração salina elevada, ocasionada principalmente pela presença de íons $\mathrm{Na}^{+}$e $\mathrm{Cl}^{-}$, podem causar desbalanço iônico na interfase solo/planta alterando o crescimento e a produção de matéria seca nas plantas. Em relação ao efeito do fator doses de $\mathrm{N}$ sobre a massa foliar aos 25 DAS, observou-se que o modelo de regressão ao qual os dados se ajustaram (aos 25 DAS), foi o quadrático (Figuras 3 e 4B). A primeira das figuras referidas mostra uma resposta positiva da obtenção de MFF ao aumento da dose de $\mathrm{N}$ até ao valor de $105 \mathrm{mg} \mathrm{kg}^{-1}$, valor este a que corresponde a máxima MFF estimada para as plantas $(0,80 \mathrm{~g})$ no intervalo em estudo (40 a $160 \mathrm{mg}$ de $\mathrm{N}$ por $\mathrm{kg}$ ). Infere-se dos resultados obtidos que a menor $\left(40 \mathrm{mg} \mathrm{kg}^{-}\right.$ ${ }^{1}$ ) e a maior $\left(160 \mathrm{mg} \mathrm{kg}^{-1}\right)$ dose de $\mathrm{N}$ foram prejudiciais em termos de produção de MFS . O que ilustra a afirmação de que o suprimento inadequado de nutrientes, tanto pela falta como pelo excesso, pode provocar restrições ao crescimento das plantas e altera as relações entre a biomassa aérea e radicular (Bovi et al., 1999). Segundo as equações de regressão calculadas para a relação MFS - doses de N (Figura 4B), aos 35 DAS há um acréscimo linear na MFS de $6,64 \%$ por cada aumento de $40 \mathrm{mg} \mathrm{kg}^{-1}$ da dose de nitrogênio aplicado; já aos 89 DAS o efeito foi inverso, ocorrendo um decréscimo linear na MFS de $7,89 \%$ por cada aumento de $40 \mathrm{mg} \mathrm{kg}^{-1}$ da dose de $\mathrm{N}$ aplicado. Supõe-se que o resultado aos 89 DAS, seja consequência do fato de, nessa época, a maioria das plantas estarem já com as suas folhas em estádio de senescência.

De acordo com os resultados do teste $\mathrm{F}$ (Tabela 3) a avaliação realizada aos 35 DAS mostra que a área foliar do girassol foi afetada ( $<<0,01)$ pela salinidade da água de irrigação. Nessa data, o aumento da salinidade da água causou um decréscimo de 53,12\% $\left(404 \mathrm{~cm}^{2}\right)$ na $\mathrm{AF}$ das plantas irrigadas com água de CEa de $3,0 \mathrm{dS} \mathrm{m}^{-1}$ em relação às plantas sob irrigação com a água de menor salinidade (Figura 5A). O decréscimo da $\mathrm{AF}$, assim como a diminuição observada no valor de NF, estão possivelmente relacionados com um dos mecanismos de adaptação da planta ao stresse salino (a diminuição da superfície transpirante) e, consequentemente, a redução da perda de água por transpiração - fato este que pode aumentar a eficiência no uso da água e minimizar a acumulação de sais na planta (TESTER e DAVENPORT, 2003). 

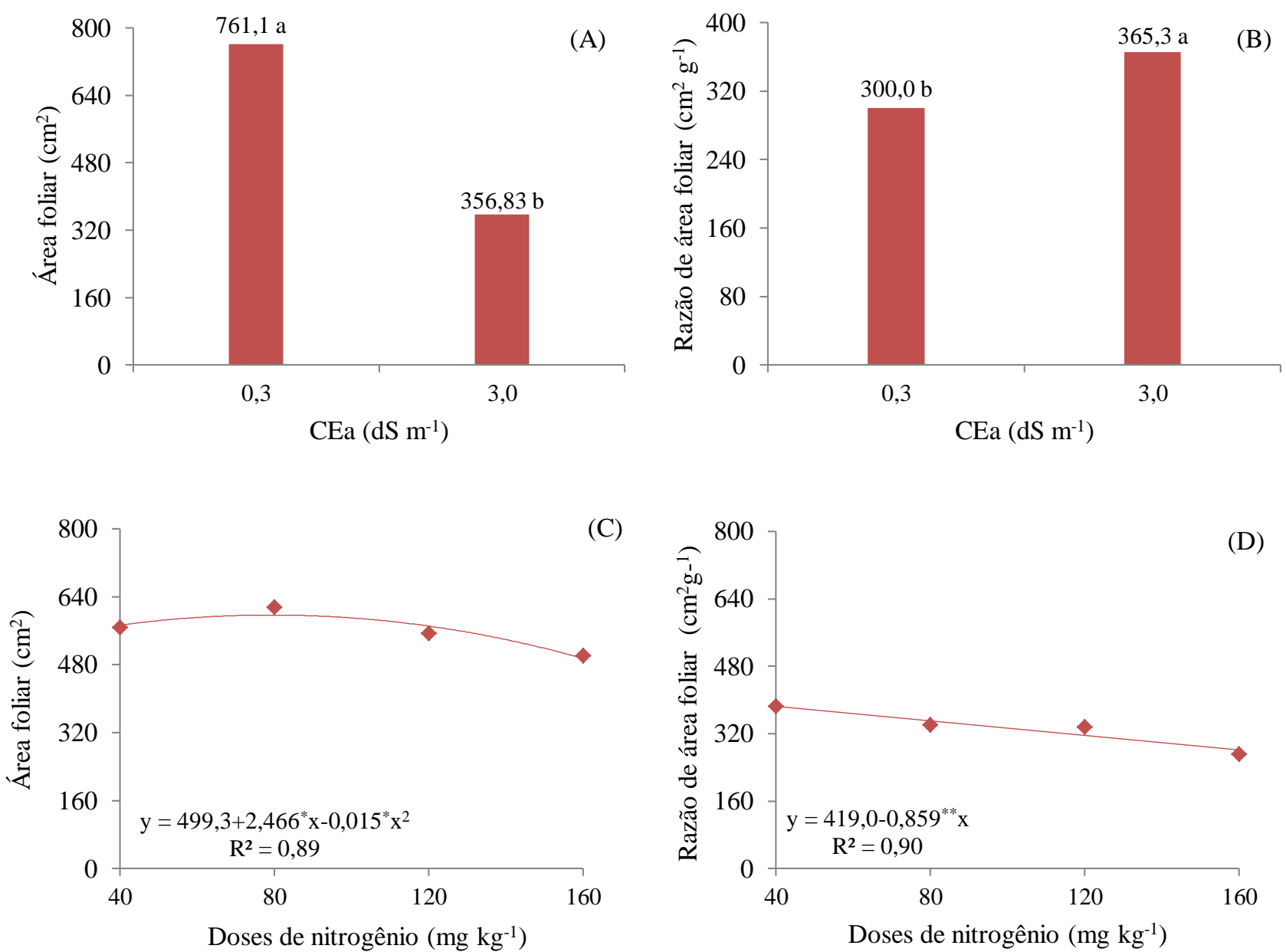

Médias seguidas pela mesma letra nas colunas, não diferem entre si a nível de 0,05 de probabilidade pelo teste de Tukey.

Figura 5. Área foliar (A) e razão da área foliar (B) aos 35 DAS em função da salinidade da água de irrigação - (CEa); e área foliar (C) e razão da área foliar (D) do girassol cv. Embrapa 122/V- 2000 aos 35 DAS em função doses de nitrogênio

Em contrapartida, a razão de área foliar aos 35 DAS sofreu um pequeno acréscimo e pode-se inferir, a partir da equação de regressão constante da Figura 5B, que as plantas sujeitas a uma salinidade mais elevada apresentaram maior quantidade de material fotossintetizante em relação à massa da matéria seca total. Diferentemente dos resultados obtidos no presente estudo, Cavalcanti et al. (2005) não observaram alterações na RAF de plantas de mamona em consequência do aumento da salinidade da água de irrigação.

Observa-se ainda, a partir da equação de regressão quadrática relativa ao efeito das doses de N sobre a AF (Figura 5C), que o valor mais elevado para área foliar $\left(596,9 \mathrm{~cm}^{2}\right)$ corresponderia à aplicação de uma dose de 79 mg de N. De acordo com Fernández et al. (1994) o $\mathrm{N}$ influencia não só a taxa de crescimento foliar, mas principalmente a divisão celular, determinando, desta forma, o tamanho final das folhas e, fazendo com que este elemento seja um dos fatores determinantes da taxa de acumulação de biomassa.

Em relação à RAFaos 35 DAS, e com base na equação de regressão apresentada (Figura 5D), observou-se um decréscimo linear da RAF da ordem de $8,99 \%$ por cada aumento de $40 \mathrm{mg} \mathrm{kg}^{-1}$ na dose de $\mathrm{N}$ aplicado. $\mathrm{O}$ nitrogênio é o nutriente mais limitante para muitas culturas no mundo, e o seu uso eficiente é de extrema importância econômica para os sistemas de produção. Além do mais, a dinâmica natural do nitrogênio e a perda deste no sistema solo-planta criam um desafio único para seu correto manejo (FAGERIA e BALIGAR, 2005). 


\section{CONCLUSÕES}

1. A irrigação com água salina de $\mathrm{CE} 3,0 \mathrm{dS}$ $\mathrm{m}^{-1}$ afetou o crescimento das plantas de girassol cv. Embrapa 122/V-2000, provocando reduções no número de folhas, na altura de planta, na massa foliar fresca e seca e na área foliar.

2. O fornecimento de nitrogênio promove aumento na massa fresca e seca de folhas e área foliar e as fontes de $\mathrm{N}$, sendo que a ureia e o nitrato de cálcio contribuíram para o incremento no número de folhas aos 25 DAS e altura de plantas aos 25,35 e 70 DAS.

3. A interação entre os fatores salinidade da água de irrigação, fontes e doses de nitrogênio não influenciou nenhuma das variáveis estudadas (número de folhas, altura da planta, massa foliar (fresca e seca), área foliar e razão de área foliar), demonstrando que o aumento da dose de $\mathrm{N}$ não minora os efeitos da salinidade em girassol.

\section{REFERÊNCIAS}

ALVES, N. S.; GHEYI, H. R.; UYEDA, C. A.; SOARES, F.A.L.; NOBRE, R. G.; CARDOSO, J. A. F. Uso de águas salinas e adubação nitrogenada no cultivo da mamoneira BRSEnergia. Revista Brasileira de Agricultura Irrigada, v.6, n. 2, p'.151-163, 2012.

ASCH, F.; DINGKUHN, M.; DORFFING, K. Salinity increases $\mathrm{CO}_{2}$ assimilation but reduces growth in field grown irrigated rice. Plant and Soil, v.218, n.1-2, p. 1-10, 2000.

AUDRY, P.; SUASSUNA, J. A salinidade das águas disponíveis para a pequena irrigação no sertão do Nordeste: caracterização, variação sazonal, limitação do uso. Recife: CNPq.. 128p. 1995.

AYERS, R. S.; WESTCOT, D.W. A qualidade da água na agricultura. 2.ed. Campina Grande: UFPB. 153p. (Estudos da FAO, Irrigação e Drenagem, 29 revisado 1). 1999.
BOVI, M. L. A.; SPIERING, S. H, BARBOSA, A. M. M (1999) Densidade radicular de progênies de pupunheira em função de adubação NPK. Horticultura Brasileira, v.17, n.3, p.186-193, 1999.

BRUGINSKI, D. H.; PISSAIA, A. Cobertura nitrogenada em girassol sob plantio direto na palha: II - morfologia da planta e partição de massa seca. Scientia Agrária, v.3, n.2, p.4753, 2002.

CAVALCANTI, M. L.; FERNANDES, P.D.; GHEYI, H. R.; BARROS JÚNIOR, G.; SOARES, F. A. L.; SIQUEIRA, E. C. Tolerância da mamoneira BRS 149 à salinidade: germinação e características de crescimento. Revista Brasileira de Engenharia Agrícola e Ambiental, v. 9 (Suplemento), p.57-61, 2005.

CLAESSEN, M. E.C (org.). Manual de métodos de análise de solo. 2.ed. rev. atual. Rio de Janeiro: Embrapa-CNPS. 212p. (Embrapa-CNPS. Documentos, 1). 1997.

DEL AMOR, F. M.; RUIZ-SANCHEZ, M. C.; MARTINEZ, V.; CERDA, A. Gás Exchange, water relations, and ions concentrations of saltstressed tomato and melon plants. Journal of Plant Nutrition, v. 23, n.9, p.13151325, 2000.

EMBRAPA - Empresa Brasileira de Pesquisa Agropecuária. Girassol Embrapa 122/V-2000. Londrina, 2006. (Folder n. 04/2006).

FAGERIA, N. K.; BALIGAR, V. C. (2005) Enchancing nitrogen use efficiency in crop plants. Advances in Agronomy, v.88, n.1, p.97-185, 2005.

FAGUNDES, J. D.; SANTIAGO, G.; MELLO, A.M. de; BELLÉ, R.A.; STRECK, N. A. Crescimento, desenvolvimento e retardamento da senescência foliar em girassol de vaso (Helianthus annuus L.): fontes e doses de nitrogênio. Ciencia Rural, v.37, n.4, p.987993, 2007. 
FERNÁNDEZ, S.; VIDAL, D.; SIMÓN, E. Radiometric characterístcs of Triticum aestivum cv. Astral under water and nitrogen stress. Internacional Journal of Remote Sensing, v.15, n.9, p.1867-1884, 1994.

FERRI, M. G. Fisiologia vegetal 1. 2. ed. São Paulo: EPU..362p. 1985.

GUEDES FILHO, D. H.; SANTOS, J. B. dos; GHEYI, H.R.; CAVALCANTE, L.F.; FARIAS, H. L. de. Biometria do girassol em função da salinidade da água de irrigação e da adubação nitrogenada. Revista Brasileira de Agricultura Irrigada, v.7, n.5, p.277-289, 2013.

MCALLISTER, C. H.; BEATTY, P. H.; GOOD, A.G. Engineering nitrogen use efficient crop plants: the current status. Plant Biotechnology Journal, v.10, n.9, p.10111025, 2012.

MILLER, A. J.; CRAMER, M. D. Root nitrogen acquisition and assimilation. Plant and Soil, v.274, n.1, p.3-6, 2004.

MILLER, A. J.; FAN, X.; ORSEL, M.; SMITH, S. J.; WELLS, D. M. Nitrate transport and signaling. Journal of Experimental Botany, v.58, n.9, p.2297-2306, 2007.

MUNNS, R.; TESTER, M. Mechanisms of salinity tolerance. Annual Review of Plant Biology, v. 59, n.1, p.651-681, 2008.

NOBRE, R. G.; GHEYI, H. R.; CORREIA, K. G.; SOARES, F. A. L.; ANDRADE, L. O. Crescimento e floração do girassol sob estresse salino e adubação nitrogenada. Revista Ciência Agronômica, v.41, n.3, p.358-365, 2010.

NOVAIS, R.F.; NEVES, J.C.L.; BARROS, N. F. Ensaio em ambiente controlado. In: Oliveira, A.J. (ed) Métodos de pesquisa em fertilidade do solo. Brasília: Embrapa-SEA. p. 189-253. 1991.
OLIVEIRA, F. A.; CARRILO, M. J. S.; MEDEIROS, J.F.; MARACÁ, P. B.; OLIVEIRA, M. K. T. Desempenho de cultivares de alface submetidas a diferentes níveis de salinidade da água de irrigação. Revista Brasileira de Engenharia Agrícola e Ambiental, v.15, n.8, p.771-777, 2011.

OLIVEIRA, F. de A.; OLIVEIRA, F. R.A.; CAMPOS, M. de S.; OLIVEIRA, M. K. T. de, MEDEIROS, J. F. de; SILVA, O.M. dos P. Interação entre salinidade $\mathrm{e}$ fontes de nitrogênio no desenvolvimento inicial da cultura do girassol. Revista Brasileira de Ciências Agrárias, v.5, n.4, p.479-484, 2010.

RHOADES, J.D.; KANDIAH, A.; MASHALI, A. M. Uso de águas salinas para produção agrícola. UFPB, 117p. 2000. Estudos da FAO, Irrigação e Drenagem, 48, revisado.

SANGOI, L.; ERNANI, P.R.; BIANCHET, P. Desenvolvimento inicial do milho em função de doses e fontes de nitrogênio aplicadas na semeadura. Biotemas, v. 22, n.4, p.53-58, 2009.

SANTOS JÚNIOR, J. A.; GHEYI, H. R.; GUEDES FILHO, D. H.; DIAS, N. da S.; SOARES, F. A. L. Cultivo de girassol em sistema hidropônico sob diferentes níveis de salinidade. Revista Ciência Agronômica, v.42, n.4, p.842-849, 2011.

SANTOS, A. C.; ANDRADE, A. P.; LIMA, J. R. S.; SILVA, I.F.; CAVALCANTE, V.R. Variabilidade temporal da precipitação pluvial: nível de nitrogênio no solo e produtividade de cultivares de girassol. Ciência Rural, v. 32, n.5, p.757-764, 2002.

SILVA, E. C.; NOGUEIRA, R. J. M. C.; ARAÚJO, F.P.; MELO, N.F.; AZEVEDO NETO, A. D. Physiological responses to salt stress in young umbu plants. Environmental and Experimental Botany, v. 63, n.1-3, p.147157, 2008.

SILVA, T. G. F.; ZOLNIE, S.R.; GROSSI, J.A.S.; BARBOSA, J.G.; MOURA, C.R.W.; 
MUNIZ, M.A. (2009) Crescimento do girassol ornamental cultivado em ambiente protegido sob diferentes níveis de condutividade elétrica de fertirrigação. Revista Ceres, v.56, n.5, p.602-610, 2009.

TESTER, M.; DAVENPORT, R. $\mathrm{Na}^{+}$ tolerance and $\mathrm{Na}^{+}$transport in higher plants. Annals of Botany, v. 91, n.5, p.503527, 2003.

TRAVASSOS, K.D.; GHEYI, H. R.; SOARES, F.A.L.; BARROS, H. M. M.; DIAS, N. da S, UYEDA, CA, SILVA, F. V. da. Crescimento e desenvolvimento de variedades de girassol irrigado com água salina. Irriga, Edição Especial:324-339, 2012.

TRAVASSOS, K. D.; SOARES, F. A.L.; GHEYI, H. R.; DIAS, N. da S, NOBRE, R.G. Crescimento e produção de flores de girassol irrigado com água salobra. Revista Brasileira de Agricultura Irrigada, v.5, n.2, p.123-133, 2011.

YAHYA, A. salinity effects on growth and uptake and distribution on sodium and some essential mineral nutrients in sesame. Journal of Plant Nutrition, v.21, n.2, p.1439-1451, 1998. 